\title{
Gefahren des Taubenhaltens
}

— Ein 68-jähriger Taubenzüchter nahm wegen einer chronischen lymphatischen Leukämie Alemtuzumab ein. Er stellte sich wegen einer seit drei Monaten bestehenden, nicht heilenden Ulzeration im Bereich seines Unterarm-Amputationsstumpfes vor. Die traumatische Amputation des linken Unterarms war 40 Jahre früher passiert. Der Mann trug keine Prothese.

Ehe es zur Ulzeration kam, beobachtete der Mann im Stumpfbereich ein druckschmerzhaftes gerötetes Knötchen. Eine antibiotische Therapie durch den Hausarzt blieb ohne Wirkung. In einer Biopsie aus dem Ulkusgrund fanden sich Kryptokokken, worauf eine Behandlung mit Amphotericin B und Flucytosin erfolgte. Das Ulkus bildete sich im Lauf weniger Wochen zurück.

\section{Kommentar}

Taubenkot enthält reichlich Cryptococcus neoformans. Bei immunsupprimierten $\mathrm{Pa}$ tienten kann eine Kryptokokkeninfektion einen letalen Ausgang nehmen.

H. S. FÜESSL =

- R. S. Llewellyn und E. Domanne (Korres.: rllewellyn@doctors.net.uk): Hazards of keeping pigeons. BMJ 2013; 346: f1039

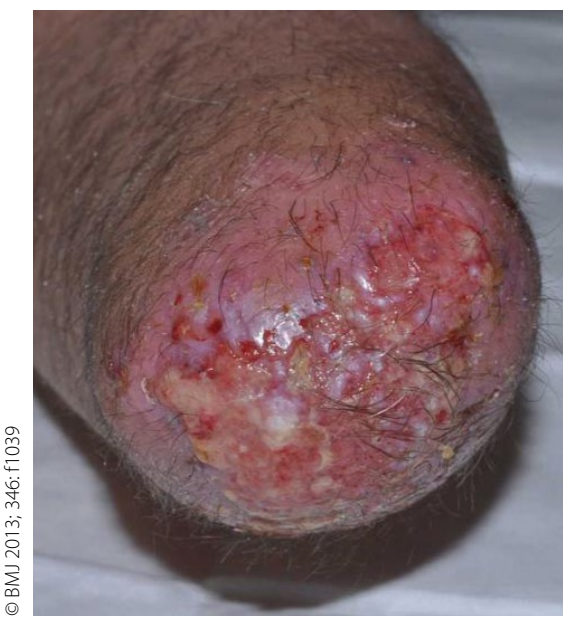

Kryptokokkeninfektion am Amputationsstumpf. 